\title{
Is There a Sympathetic Regulation of the Efficiency of Energy Utilization?
}

\author{
L. Girardier and J. Seydoux \\ Département de Physiologie, Ecole de Médecine, Genève, Switzerland
}

Summary. Brown adipose tissue, a well known effector of regulatory thermogenesis found in mammals, is unique in its ability to steadily increase its heat production several fold for very long periods of time. It constitutes a shunt of energy flow between food intake and heat dissipation, it is activated through its sympathetic nerve supply. There are evidence in the rat, that brown adipose tissue is activated following overfeading, thus decreasing food efficiency and determining resistance to obesity. Genetically obese (ob/ob) mice fed and kept at $22^{\circ} \mathrm{C}$ lack the possibility of activating their brown fat energy shunt; they are known to be poorly resistant to cold stress despite their large insulation. This is taken as a further circumstantial evidence of an overlap in thermal and food efficiency regulatory systems in rodents through sympathetically controlled brown fat as a common effector.

Key words: Brown adipose tissue, cold-induced thermogenesis, diet-induced thermogenesis, genetically obese rodents, metabolic efficiency

A great challenge in bioenergetics today is to explain how it is that apparently similar individuals can maintain body weight balance with widely differing food intakes. There are several reports of pairs of human individuals of the same weight and similar levels of physical activity for which one individual eats twice as much as the other [1]. This variability of individual food requirement while maintaining constant weight must be caused by a variability in the efficiency of food utilization.

\section{The Efficiency of Energy Utilization}

The concept of efficiency of energy utilization by a living organism is much more complex than that developed by engineers for engines. A simple engine consumes fuel to do work, and the energy that does not appear as work is dissipated as heat. Since the external work is the only item of interest for the engineer, the efficiency is defined as the fraction of the total energy transformed which appears as work. A living organism may be considered as a machine which, in addition to performing work, carries out its own maintenance and furthermore, in homeotherms, regulates its own operating temperature.

The energy cost necessary to maintain the composition of the machine and its temperature is high, accounting for about two thirds of the total expenditure in sedentary man, and any definition of the overall efficiency of the organism should take this into account. For operational purposes metabolic efficiency can be expressed as an inverse of the mean energy input for individuals to maintain a constant mean weight, core temperature and level of physical activity.

\section{The Pathways Leading from Energy Input to Energy Output}

The overall equation for the exchange of energy between the individual and its environment is

Energy In $\left(\dot{\mathrm{E}}_{\text {in }}\right)=$ Energy Out $\left(\dot{\mathrm{E}}_{\text {out }}\right)$

for values integrated over long periods of time. Over shorter periods, the exchange may depart significantly from equality as stores are used and deficits replenished. Figure 1 depicts diagrammatically the main pathways from $\dot{\mathrm{E}}_{\text {in }}$ to $\dot{\mathrm{E}}_{\text {out }}$. Energy enters the system as food with a caloric value depending on its chemical nature. Maintenance requires investment of chemical energy for anabolic processes compensating for break-down of biomolecules and internal work. It is required for powering a convective system that distributes fuel and oxygen to local machinery and removes the waste products and heat. Food may appear in storage as carbohydrate or fat or as a part of the lean body mass. 


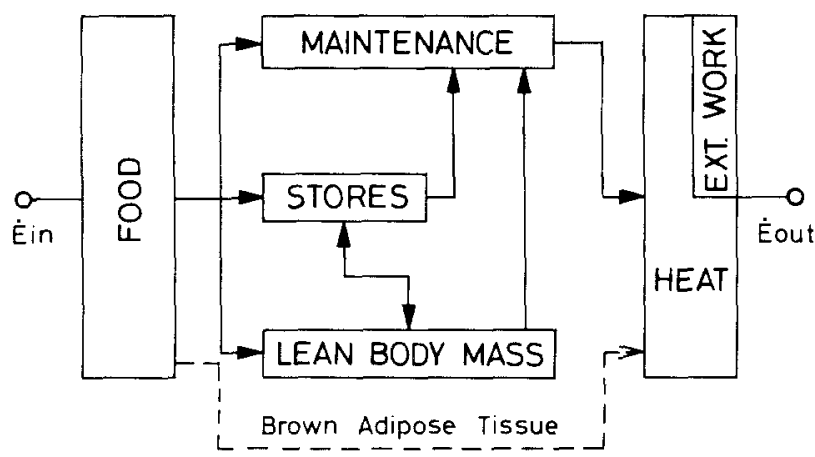

Fig. 1. Main pathways from energy intake $\left(\dot{\mathrm{E}}_{\mathrm{in}}\right)$ to energy output $\left(\dot{\mathbf{E}}_{\text {out }}\right)$

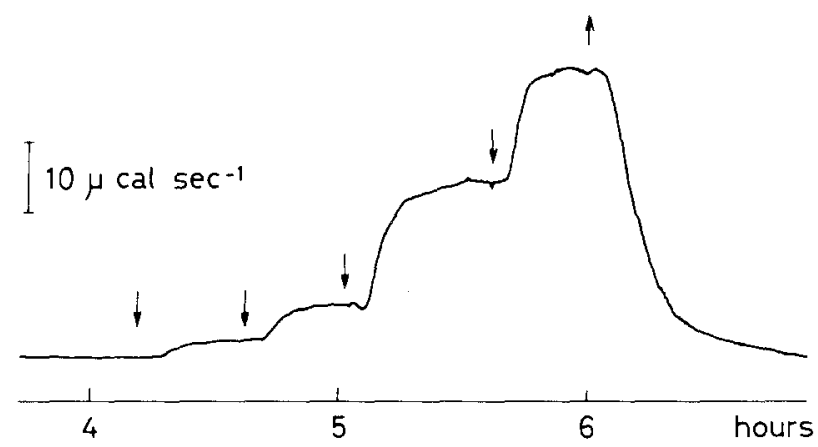

Fig. 2. Heat dissipation (in $\mu \mathrm{cal} / \mathrm{sec}$ ) of isolated brown adipose tissue as measured by direct calorimetry. The reading shows the response of the fat pad to increasing concentrations of noradrenaline $(35,60,160$ and $600 \mathrm{nmol})$ at the downward arrows. The upward arrow depicts removal of the final dose

The equality of $\dot{\mathrm{E}}_{\text {in }}$ and $\dot{\mathrm{E}}_{\text {out }}$ can be fulfilled for different absolute intensities of energy flow. Genetic factors seem to determine the mean required energy flow. Individuals possessing low absolute flow (that is, according to our definition, a high efficiency of energy utilization) possess the genetic potential for obesity.

\section{Brown Fat Tissue: A Regulated Energy Shunt}

In Figure 1, the peculiar connections of brown adipose tissue (BAT) in the energy flow diagram are illustrated. This tissue represents a shunt between $\dot{\mathrm{E}}_{\text {in }}$ and $\dot{\mathrm{E}}_{\text {out }}$ as discussed below.

Brown adipose tissue is found only in mammals and occurs at multiple sites within an individual. It is highly developed in small animals such as rodents but is also found in larger mammals such as man. It is densely innervated by sympathetic nerve fibres and is unique in its ability to increase steadily its heat production over a several-fold range for very long periods of time. Figure 2 shows heat production of BAT in response to a stepwise increase of the concentration of noradrenaline in the perifusion medium [2]. This increase of metabolism is mediated by betaadrenergic receptors.
BAT is an effector of the thermoregulatory system. Its activation upon cold-exposure of the animal is practically immediate, and its fat stores are preferentially utilized for heat production. Lindberg et al. [3] showed that a hamster exposed to 3-day starvation at $25^{\circ} \mathrm{C}$ loses about $10 \%$ of its BAT triglyceride (TG) stores, whereas if starved at $4{ }^{\circ} \mathrm{C}$, it loses more than $30 \%$ of its stores in 2 hours, $96 \%$ in three days and dies in four days. A fed hamster however, under the same cold stress, survives, and half ot its BAT triglyceride stores are maintained. Since the white fat stores are not severely influenced during this period of stress, it is obvious that the capacity of white fat to provide TG or fatty acids to BAT is not sufficient to support the thermogenic function of this tissue. Alimentary TG, however, is able to provide the required amounts. Thus, when stimulated, BAT behaves as a shunt for the energy flow between $E_{\text {in }}$ and $\mathrm{E}_{\text {out }}$. Its activation results in a decrease in the efficiency of energy utilization and consequently a sympathetic regulation of metabolic efficiency appears to exist, at least in small mammals.

\section{Brown Fat Tissue and Dietary-induced Thermogenesis in the Rat}

Dietary-induced thermogenesis is the generally accepted term to describe both the rise in heat production following the consumption of a meal and the elevated heat production observed chronically during a period of a high level of nutrition. The former is the classical "specific dynamic action" and the latter the "luxus consumption". It is now clear that dietaryinduced thermogenesis is not specifically related to the protein content of the diet, and that it increases with food consumption. It is a metabolic response that tends to modulate the effects of fluctuations of food intake. Rothwell an Stock [4] have shown that, in the rat, this form of thermogenesis, like coldinduced thermogenesis, involves activation of the sympathetic nervous system and stimulation of brown adipose tissue. They found that, during voluntary over-eating in rats, resting oxygen consumption $\left(\dot{\mathrm{V}}_{\mathrm{O}_{2}}\right)$ and the mass of interscapular brown fat increased. There was a remarkable correlation between the two parameters which was not apparent in control animals. A beta-adrenergic blocker, propranolol, decreased $\dot{\mathrm{V}}_{\mathrm{O}_{2}}$ during overeating but not during control periods. They concluded that BAT may determine metabolic efficiency and resistance to obesity in the rat. To what extent can this conclusion be extrapolated to larger mammals and, for instance, to man? In man, brown fat is found [5] but certainly not in large quantities. It must be emphasized however that BAT is a very powerful energy dissipator. In the cold-adapted rat submitted to noradrenaline, 

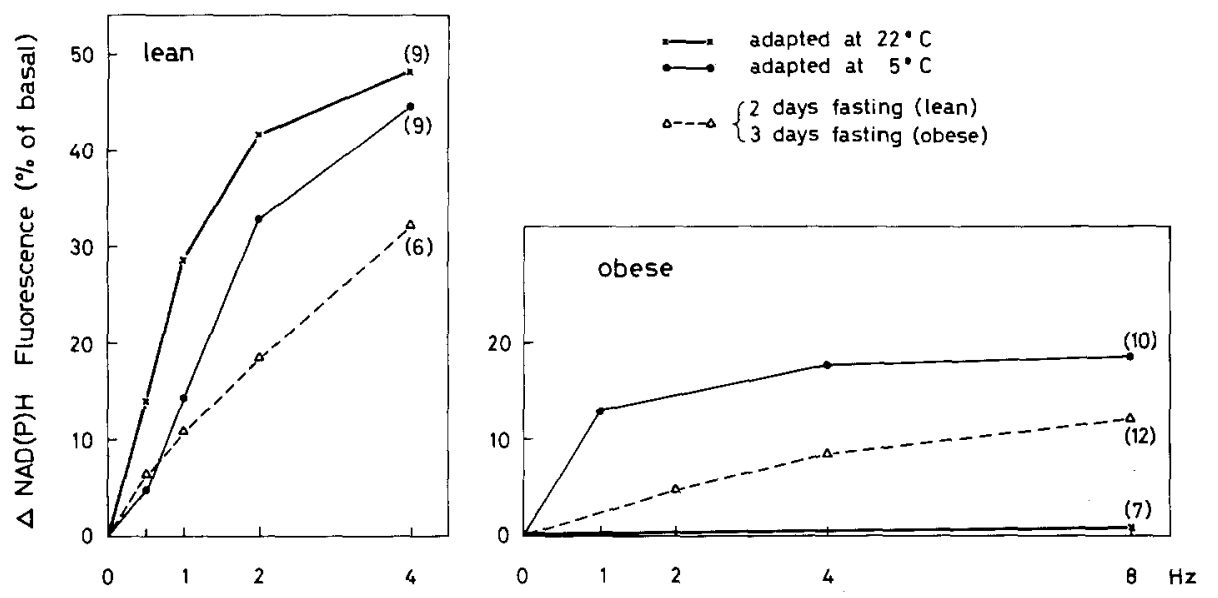

Fig. 3. In vitro electrical stimulation of the nerve supply to brown adipose tissue. Effect of stimulation frequency on the redox state of nicotinamide adenine nucleotides as measured by reflection spectrofluorimetry. obese: ob/ob mice - lean: $+/+$ mice
BAT can receive as much as $34 \%$ of the cardiac output and produce up to $60 \%$ of the regulatory thermogenesis. Yet it represents only $1-2 \%$ of body weight [6]. In larger mammals the relative BAT mass seems to be lower, but if it is as active per unit weight as in the rat, it could, when activated, reduce the overall metabolic efficiency of the organism. The integral over long periods of time of even small improvements in the day-to-day energy balance could become significant.

\section{Brown Fat in Genetically Obese Animals}

An obvious model for the study of the role of brown fat as an effector for metabolic efficiency regulation is the genetically obese rodent. These animals have a remarkable efficiency of energy utilization. Using pair-feeding experiments, Coleman showed that diabetic obese $(\mathrm{db} / \mathrm{db})$ mutants utilize food more efficiently than normal mice, and, when restricted to $50 \%$ of the amount of food eaten by the normal mouse, these mutants maintain normal growth rates but remain obese (Coleman, D. L., personal communication). During fasting, their fat stores are utilized more efficiently.

The price of this high efficiency is a lower core temperature and an impairment in regulatory thermogenesis when exposed to cold stress. It has been shown that obese mice exposed to $4^{\circ} \mathrm{C}$ may die of hypothermia in a few hours, whereas lean control mice will survive $[7,8]$. BAT is found in obese mice, and the quantity present is about three times greater than that of lean controls, but its total protein content is only $2 / 3$ of that of controls, indicating that TG stores are significantly increased in BAT of obese mice.

To test whether the BAT of obese mice is functionally active, its production of reducing equivalents in response to nerve stimulation was measured and compared to that of the lean control. This was performed by monitoring the surface-emitted NAP(P)H fluorescence by a spectrofluorimetric method during electrical nerve stimulation at various frequencies [9]. As illustrated in Figure 3, it was found that whereas BAT from lean controls responded with a large, frequency-dependent, NAD(P) reduction, there was no significant response to the stimulation in the BAT from obese mice [10]. This study indicate that their brown adipose tissue is functionally disconnected. Thus, these hyperefficient animals lack the possibility of activating their BAT energy shunt when fed and kept at $22^{\circ} \mathrm{C}$ through neural mechanisms. This also accounts for at least a part of their poor resistance to cold stress despite their large insulation.

It is interesting to note that this tissue can be reconnected by two manoeuvres: fasting and progressive cold adaptation to $4{ }^{\circ} \mathrm{C}$ (see Fig. 3).

\section{Conclusion}

Evidence has been presented for an overlap of the thermal and food-efficiency regulatory systems in rodents. This overlap is due to a common effector, the brown adipose tissue, the activity of which is controlled by its sympathetic nerve supply.

Therefore, it can be concluded that there is indeed a sympathetic regulation of the efficiency of energy utilisation in rodents. The nature of the primary signal leading to BAT stimulation and subsequent hypertrophy induced by voluntary overeating remains to be elucidated.

Acknowledgements. The authors wish to thank Mrs. Annette Jousson and Miss Claude-Anne Breitmeyer for their skilled technical assistance. This work is supported by a grant from the Swiss National Foundation for Scientific Research. No 3.285.78

\section{References}

1. Miller DS (1979) Thermogenesis and obesity. In: Somogyi JC, de Wijn JF (eds) Nutritional aspects of physical performance. Karger, Basel München Paris London New York Sydney, p 25-32 
2. Chinet A, Clausen T, Girardier L (1977) Microcalorimetric determination of energy expenditure due to active sodiumpotassium transport in the soleus muscle and brown adipose tissue of the rat. J Physiol (Lond) 265: 43-61

3. Lindberg O, Bieber LL, Houstek J (1976) Brown adipose tissue metabolism; an attempt to apply results from in vitro experiments on tissue in vivo. In: Jansky L, Musacchia XJ (eds) Regulation of depressed metabolism and thermogenesis. CC Thomas, Springfield Illinois, p 117-136

4. Rothwell NJ, Stock MJ (1979) A role for brown adipose tissue in diet-induced thermogenesis. Nature 281: 31-35

5. Heaton JM (1972) The distribution of brown adipose tissue in the human. J Anat 112: 35-39

6. Foster DO, Frydman ML (1978) Nonshivering thermogenesis in the rat. Measurements of blood flow with microspheres point to brown adipose tissue as the dominant site of the calorigenesis induced by noradrenaline. Can J Physiol Pharmacol 56: 110-112

7. Trayhurn P, James WPT (1978) Thermoregulation and non- shivering thermogenesis in the genetically obese (ob/ob) mouse. Pfliigers Arch 373: 189-193

8. Trayhurn $P$ (1979) Thermoregulation in the diabetic-obese $(\mathrm{db} / \mathrm{db})$ mouse. Pflügers Arch 380: 227-232

9. Seydoux J, Constantinidis J, Tsacopoulos M, Girardier L (1977) In vitro study of the control of the metabolic activity of brown adipose tissue by the sympathetic nervous system. J Physiol (Paris) 73: 985-996

10. Seydoux J, Assimacopoulos-Jeannet F, Giacobino JP, Girardier L (1980) Reactivation of brown adipose tissue in obese hyperglycemic ob/ob mice by fasting and cold-adaptation. Experientia 36: 700

\section{Girardier}

Department of Physiology

School of Medicine

CH-1211 Genève 4

Switzerland

\section{Discussion after Girardier's Presentation}

Pardridge: Have you tried to increase the BAT heat production of the obese mice with carnitine?

Girardier: Your suggestion is very timely since we are just now doing those experiments.

Pardridge: If BAT is like liver or muscle, this technique might well lead to increased heat production.

Goldman: Actually, since octanoate was not effective, carnitine should also not be effective.

Pardridge: Yes, but in a physiological setting, octanoate may never be a major fuel, so it is worth trying carnitine.

Goldman: I feel though that the fact that octanoate doesn't work rules out carnitine as a major explanation since mechanistically it demonstrates that the defect cannot be totally at the carnitine step. Octanoate oxidation would be perfectly normal if the defect were at the carnitine step.

Seydoux: We agree with this but since the experiment is feasible, we planned to test this point.

Goldman: Since you have not been able to normalize completely the BAT function in these animals using cold adaptation, do you believe there is a primary receptor deficit?

Girardier: We found an increase of the density of the $\beta$ receptors with no change in their affinity. This is suggestive of a denervation supersensitivity. It seems highly probable therefore that the primary lesion is in the nerve control system. If this is in fact the case, the observed cellular alterations would be secondary effects due to the lack of neural activation. The number of $\beta$ receptors was found to return to normal after cold adaptation.

Goldman: Might not your results also reflect an accelerated rate of fatty acid synthesis in these animals?

Seydoux: Yes, that also occurs.

B. Jeanrenaud: What are the mitochondria like in BAT of these mice?
Sexdoux: I have only seen an abstract which said that the cristae are not as packed and that they are swollen and larger than normal.

Bray: I believe that there is also evidence for altered mitochondrial enzyme function in these animals.

Porte: What do you think would happen if you infused noradrenaline for long periods of time?

Girardier: It would be like our cold-adaptation study; I think function might be restored to normal.

Porte: The question is why do these animals have a nonfunctional BAT system and is this an important mechanism in their weight gain?

Seydoux: We certainly feel that it is.

Porte: If you had some way to turn on this tissue, would these animals find some other way to gain weight?

Girardier: We don't have that answer, but we know from Coleman's experiments that the altered efficiency of these animals, even in pair-feeding, is remarkable.

Havrankova: How do you think the hyperinsulinemia of these animals interacts with the nervous system, especially since you have shown that starvation (and presumably a reduction of the insulin levels) reverses the problem?

Seydoux: There may well be an important relationship there since both the improved BAT function and the hyperinsulinemia went only partway toward the control values.

Havrankova: Does the defect of the BAT precede or follow the increase of insulin in the young animal?

Seydoux: We have found the defect to be present by four days of age, and I don't believe the insulin is elevated then.

Bray: I believe that hyperinsulinemia has been reported by six days of age, and it's probably too difficult to measure it much before that, so no conclusion should probably be made regarding its age of onset. 